\title{
Desert lizard diversity worldwide: effects of environment, time, and evolutionary rate
}

\author{
Héctor Tejero-Cicuéndez ${ }^{1, *}$, Pedro Tarroso ${ }^{1,2}$, Salvador Carranza ${ }^{1}$, Daniel L. Rabosky ${ }^{3}$ \\ ${ }^{1}$ Institute of Evolutionary Biology (CSIC-Universitat Pompeu Fabra), Passeig Marítim de la \\ Barceloneta 37-49, Barcelona, Spain.
}

${ }^{2} \mathrm{CIBIO} / \mathrm{InBIO}$, Research Centre in Biodiversity and Genetic Resources, Universidade do Porto, Campus Agrário de Vairão, Rua Padre Armando Quintas, Vairão, Vila do Conde, Portugal

3 Museum of Zoology, Department of Ecology \& Evolutionary Biology, University of Michigan, 1105 N. University, Biological Sciences Building, Ann Arbor, MI 48109

* Correspondence to be sent to: Institute of Evolutionary Biology (CSIC-Universitat Pompeu Fabra), Passeig Marítim de la Barceloneta 37-49, Barcelona, Spain; E-mail: cicuendez93@gmail.com ORCID ID: https://orcid.org/0000-0001-8151-465X

The authors declare no conflicts of interest.

\begin{abstract}
Biodiversity is not uniformly distributed across the Earth's surface, even among physiographically comparable biomes in different biogeographic regions. For lizards, the world's large desert regions are characterized by extreme heterogeneity in species richness, spanning some of the most species-rich (arid Australia) and species-poor (central Asia) biomes overall. Regional differences in species diversity may arise as a consequence of the interplay of several factors (e.g., evolutionary time, diversification rate, environment), but their relative importance for biogeographic patterns remains poorly known. Here we use distributional and phylogenetic data to assess the evolutionary and ecological drivers of large-scale variation in desert lizard diversity. We specifically test whether diversity patterns are best explained by differences in the ages of arid-adapted lineages (evolutionary time hypothesis), by regional variation in speciation rate, by geographic area of the arid systems, and by spatial variation related to environment (climate, topography, and productivity). We found no effect of recent speciation rate and geographic area on differences in desert lizard diversity. We demonstrate that the extreme species richness of the Australian deserts cannot be explained by greater evolutionary time, because species began accumulating more recently there than in more species-poor arid regions. We find limited support for relationships between regional lizard richness and environmental variables, especially temperature, but these effects were inconsistent across deserts. Our results provide evidence against several classic hypotheses for interregional variation in species richness, but also highlight the complexity of processes underlying vertebrate community richness in the world's great arid systems.
\end{abstract}

Keywords: Arid regions; regional diversity; species richness; diversity anomalies; evolutionary time; speciation rate. 


\section{INTRODUCTION}

What causes the dramatic differences in species diversity that we observe among different regions of the world? The latitudinal diversity gradient (LDG) is perhaps the most famous spatial diversity pattern, but species richness can vary greatly even among physiographically similar but geographically distinct biomes (Pianka, 1986; Ricklefs \& Schluter, 1993; Kelt et al., 1996; Valente \& Vargas, 2013; Couvreur, 2015). There is overall agreement that multiple ecological and evolutionary factors influence the assembly of regional species pools through their effects on dispersal, speciation, and extinction (Ricklefs, 1987; Cracraft, 1992; Rabosky, 2009; Wiens, 2011; Weber et al., 2017), but we still lack general consensus on the relative importance of processes that shape regional differences in species richness (Mittelbach et al., 2007; Belmaker \& Jetz, 2015).

A key challenge with large-scale assessments of species richness is that climatic, historical, and geographic hypotheses for species diversity may covary, such that disentangling their relative contributions to species diversity may be difficult or impossible (Rabosky \& Hurlbert, 2015; Etienne et al., 2019). For example, in the case of the LDG, the tropics are generally older, larger, warmer, and more productive than extratropical regions. These factors are generally predicted to affect species richness in the same direction, and it is therefore difficult to isolate the effects of any single process on the overall LDG. In contrast, regional differences in species richness among climatically-matched regions can facilitate tests of the role of historical and geographic factors on diversity, by controlling - at least in part - for broad-scale differences in climate between regions. Many previous studies have addressed the role of evolutionary processes in generating these "diversity anomalies" (Ricklefs \& Latham, 1993) through intercontinental comparisons of tropical rainforests (Couvreur, 2015), temperate floras (Latham \& Ricklefs, 1993; Qian \& Ricklefs, 2000), Mediterranean floras (Valente \& Vargas, 2013), mangrove ecosystems (Ricklefs \& Latham, 1993), and others.

One of the most striking regional diversity anomalies is the exceptional species richness of Australian desert lizards relative to lizards from other deserts (Pianka, 1969, 1971, 1972). Arid Australia has long been known to have outstanding lizard diversity at the biogeographic scale (i.e., the total number of species in the arid zone) compared to other arid systems of the world (Pianka, 1985, 1986). In a recent synthesis of global reptile distributions, Roll et al. (2017) found strong support for exceptional regional diversity (richness in one-degree grid cells) of lizards in arid Australia. This diversity holds not only in comparison to other arid systems, but even in comparison to lowland tropical rainforests (Roll et al., 2017). At the local scale, more than 70 species of lizards (non-snakes) can occur in regional sympatry in arid Australia, a number that far exceeds those for the world's second-most species-rich lizard communities (e.g., Amazon rainforest, with 25-35 species; Duellman, 2005; Rabosky et al., 2019). Numerous hypotheses have been proposed to explain these dramatic differences in the number of species, including vegetative structure, habitat specificity and heterogeneity, termite abundance, and other ecological, biogeographic and historical factors (Pianka, 1972, 1989; Morton \& James, 1988).

The outstanding richness of Australian lizards at local, regional, and biogeographic scales (Pianka, 1969, 1986), suggests the possibility that ecological and evolutionary factors cascade upwards and/or downwards to influence species richness at larger (or smaller) spatial scales. For instance, analyzing range size and overlap for the diverse ( $\sim 100$ species) Australian lizard genus Ctenotus, James \& Shine (2000) concluded that the high local species richness might be related to the large area of the arid zone, and the high regional diversity can be explained by the wide distribution ranges favored by climate homogeneity. Thus, local richness may, at least in part, reflect processes that contribute to overall high species diversity within 
the biogeographic and regional species pools (Ricklefs, 1987, 2004), such that evolutionary and historical factors operating at regional-biogeographic scales also shape species richness at local scales.

High levels of species diversity can be the outcome of different, but not mutually exclusive, factors (Jablonski et al., 2017). For example, high diversity might be simply due to the relatively ancient and undisturbed history of one region and the lineages within (evolutionary time hypothesis; Wallace, 1878; Fischer, 1960; Fine \& Ree, 2006; Mittelbach et al., 2007). Net diversification rates, either through faster speciation or lower extinction, might also contribute to elevated species richness (Schluter \& Pennell, 2017). Other explanations include physical characteristics of the regions, which in turn might affect species richness through their impact on evolutionary rates or through their impact on the level at which diversity is regulated by diversity-dependent factors. Large geographic areas may offer more opportunities for speciation than smaller regions (Rosenzweig \& Sandlin, 1997), and climate and topography, as well as environmental heterogeneity, can further influence species diversity through impacts on primary productivity, habitat and resource availability, and diversification rate (Stein et al., 2014, 2015; Badgley et al., 2017; Cantalapiedra et al., 2018; Velasco et al., 2018; Garcia-Porta et al., 2019; Antão et al., 2020; Menéndez et al., 2020).

Here, we address the causes of the dramatic differences in lizard species richness across desert regions, with an emphasis on the exceptional diversity in arid Australia, focusing in particular on large (regional to biogeographic) spatial scales. We deliberately omit snakes from our assessment, because geographic patterns of snake diversity are markedly divergent from those for other (non-snake) squamate reptiles (e.g., "lizards"); snake diversity is generally highest in humid tropical lowlands and is broadly congruent with patterns in vascular plants, frogs, birds, and many other taxa (Roll et al., 2017). Through targeted comparisons between the largest arid systems worldwide, we test a series of hypotheses that could explain pronounced differences in lizard species richness at the biogeographic and regional scales across these (broadly-comparable physiographic) regions (Table 1). Specifically, we test whether species diversity in these systems is related to: i) the age of the arid-adapted lineages in each system (evolutionary time hypothesis), ii) within-region speciation rates, iii) geographic area of the system, iv) environmental variables that could also affect the carrying capacity of the system, as well as a measure of spatial heterogeneity for each of them: topography, mean annual temperature, mean diurnal range, annual precipitation, precipitation of the driest month, aridity, potential evapotranspiration, and productivity.

After decades of interest in these questions, the increasing availability of data and the development of new comparative phylogenetic and spatial methods allow us to finally make broad comparisons between these regions from an evolutionary perspective (Schemske \& Mittelbach, 2017). Although our analyses cannot conclusively identify the factors that cause geographic differences in species richness, they can reject potential explanations (Rabosky \& Hurlbert, 2015; Etienne et al., 2019). 
Table 1. Hypotheses to account for differences in species richness among the world's arid regions.

\begin{tabular}{|l|l|}
\hline Hypothesis & Prediction \\
\hline $\begin{array}{l}\text { Evolutionary } \\
\text { time }\end{array}$ & $\begin{array}{l}\text { Regions with high diversity have older lineages (have been accumulating species } \\
\text { for a longer time) }\end{array}$ \\
\hline Speciation rates & Faster speciation rates in regions with high diversity \\
\hline Geographic area & Larger areas harbor higher diversity \\
\hline Environment & $\begin{array}{l}\text { Environmental and topographic variables are correlated with species richness at } \\
\text { regional scale }\end{array}$ \\
\hline
\end{tabular}

\section{MATERIAL AND METHODS}

\section{Delimitation of arid systems and species categorization}

We analyzed lizard faunas in the deserts of the world, understanding lizards to represent all non-snake squamate reptiles. We first identified Earth's largest arid systems, focusing on those delineated by Olson et al., (2001) in the Biome "Deserts and Xeric Shrublands" (Biome 13). This delimitation set includes 8 main arid systems (Figure 1): Atacama, Australian desert, Central Asian desert, Gobi, Kalahari, North American desert, Persian desert, and SaharoArabian desert. These 'main arid systems' result from the aggregation of contiguous desert regions into single large arid zones (e.g., the North American arid system includes the Sonoran, Mojave, Chihuahuan and Great Basin arid subregions; the Saharo-Arabian system includes the Sahara desert and several arid regions through the Arabian Peninsula and the Horn of Africa; etc.).

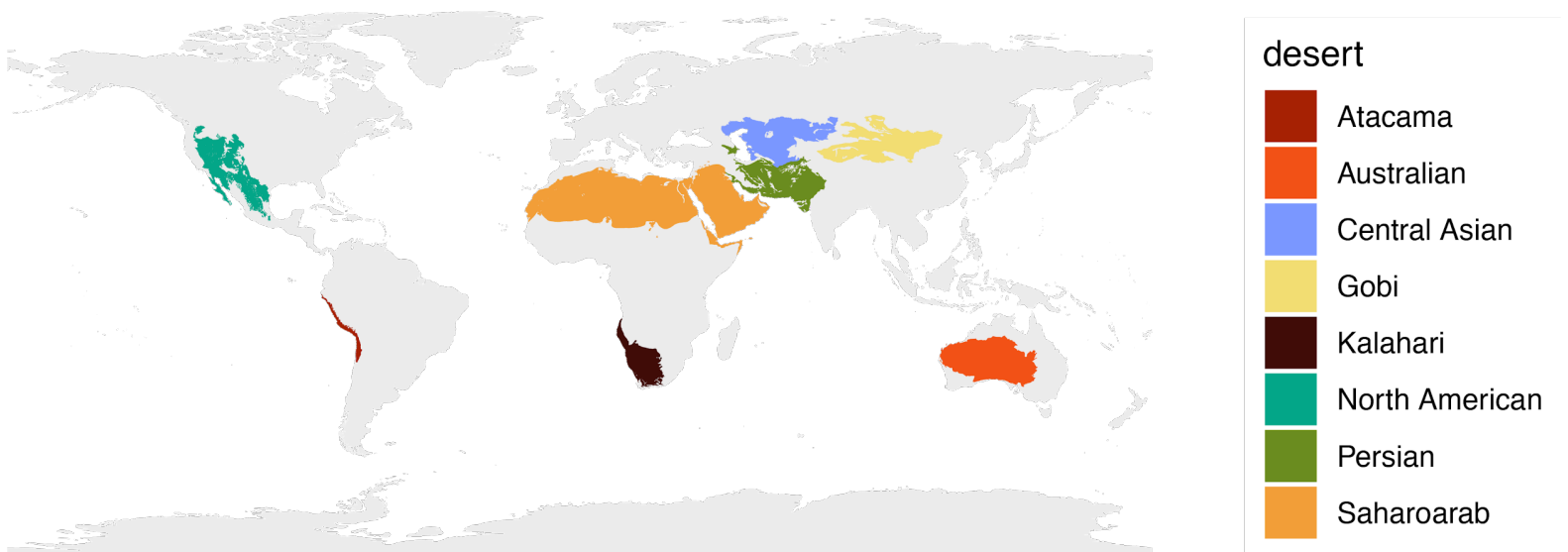

Figure 1. Delimitation of the world's arid systems.

We used lizard distribution data from a recently published global reptile dataset (Roll et al., 2017) to categorize each lizard species into arid systems, following twofold criteria: a species was considered as inhabiting a desert when at least $15 \%$ of its geographic range falls within the desert or $15 \%$ of the total desert's geographic area is occupied by the species. We tested the sensitivity of the categorization percentage across a range of thresholds, and we found that the assigned species (and total diversities) for each desert were similar across a broad range of numerical thresholds (Fig. S1). 


\section{Evolutionary time hypothesis}

The simplest hypothesis to explain geographic differences in species diversity relates to the total evolutionary time over which species have accumulated in different regions. This idea dates back to Wallace (1878), who proposed that the tropical diversity represents a 'more ancient world' than the temperate zones to explain the latitudinal diversity gradient. In order to test this hypothesis, which we refer to as the 'evolutionary time hypothesis' (Table 1), we estimated the time when lineages started diversifying within the different arid systems of the world. To do that, we reconstructed the ancestral presence of squamates in the deserts after assigning extant species to arid systems. We used the all-compatible consensus tree of squamates from Tonini et al. (2016), excluding all the species without genetic or distribution data. The inclusion of species whose phylogenetic position is imputed from taxonomic data alone leads to predictable biases in ancestral state and evolutionary rate estimation and should be avoided (Rabosky, 2015). The resulting tree contained 5,355 species (lizards and snakes). We assigned each to one arid system or categorized as "Non-arid". This classification resulted in 38 species that were assigned to more than one desert, distributed in two or more contiguous systems: Gobi, Central Asian, Persian and Saharo-Arabian deserts (Appendix 1). We applied a model of character evolution with each species coded as one out of 14 possible states: "Out of the deserts", "North American", "Central Asian", "Central Asian + Gobi", "Central Asian + Gobi + Persian", "Central Asian + Persian", "Central Asian + Persian + Saharo-Arabian", "Atacama", "Australian", "Gobi”, "Kalahari”, "Persian", "Persian + Saharo-Arabian", "Saharo-Arabian". For the ancestral state estimation we used the function 'make.simmap' from the R package phytools (Revell, 2012), with an equal-rates model and 100 simulations. For phylogenetic data manipulation we used the R packages geiger (Harmon et al., 2008) and treeio (Wang et al., 2020). This allowed us to estimate the age at which lizard lineages started accumulating in each arid system.

We estimated the general trajectory of lineage accumulation for each arid zone by summing the cumulative ancestral state probabilities for a given region through time (Mahler et al., 2010). This metric is clearly biased by the fact that only lineages with extant descendants contribute to the lineage totals at each point in time, and thus cannot detect earlier radiations within arid regions that failed to leave extant descendants. However, in our case, we are testing hypotheses to explain the observed phylogenetic structure of arid-zone lizard diversity, and thus it is the lineage accumulation curve for extant species that is most relevant. If evolutionary time is the dominant factor influencing species richness, we expect the lineage accumulation curve for the most species-rich deserts (e.g., Australia) to predate the curves for other major arid regions.

\section{Species richness, speciation rates and geographic area of the deserts}

Another evolutionary mechanism that might explain richness patterns is variation in diversification rates, e.g., areas and clades with higher diversification rates will presumably have higher species diversity (Table 1). In light of difficulties in estimating extinction rates from molecular phylogenies (Rabosky, 2016), we tested this hypothesis using recent speciation rates only, which is likely the parameter that can be most reliably inferred from a timecalibrated phylogeny (Louca \& Pennell, 2020). All else being equal, elevated speciation for a given biome should translate into elevated net diversification, unless extinction rates are also sufficiently increased as to offset the effects of increased speciation rates. We estimated recent speciation rates using the DR metric (Jetz et al., 2012). Although sometimes presented as an estimate of net diversification rate, DR is a much better estimate of speciation rate (Title \& Rabosky, 2019). Using the Tonini et al. (2016) pseudoposterior distribution of fully-sampled phylogenies, we calculated the mean DR metric for each of the 9,755 species across 100 trees from the posterior. The Tonini et al. (2016) phylogenies are complete at the species level but 
include approximately 4,000 species whose position was imputed from taxonomic information using a stochastic birth-death polytomy resolver (Thomas et al., 2013). DR values computed from such trees are relatively robust to biases caused by incomplete taxon sampling and afford greater power to infer variation in evolutionary rates relative to estimates that use formal sampling fractions (Chang et al., 2020). We then conducted nonparametric Kruskal-Wallis and Wilcoxon post-hoc analyses to compare lizard speciation rates among deserts to address how this metric relates with biogeographic species richness (the total number of species within each desert).

We also explored the relationship between species richness, speciation rates, and the geographic area of the arid systems, since the size of an area may affect both the species diversity and the speciation rates (Table 1; Connor \& McCoy, 1979; Rosenzweig, 1992). To do that, we compared the values of species richness, speciation rates and geographic area among deserts, looking for potential patterns to explain richness levels (e.g., highly diverse deserts with larger areas and/or faster speciation than less diverse ones). We implemented all the analyses, as well as data visualization, in the R environment (R Core Team, 2019), using the packages within tidyverse (Wickham et al., 2019).

\section{Regional richness and environmental variables}

We developed a desert lizard species richness grid overlaying the distribution data (Roll et al., $2017)$ onto an equal-area 10 arcminutes $(\sim 18 \mathrm{Km} ; \sim 0.17$ degrees $)$ resolution grid in a Behrmann equal-area projection. We investigated the potential influence of three types of environmental descriptors on desert lizard diversity patterns: topography, climate and productivity. The topography data was obtained from the Shuttle Radar Topography Mission (SRTM) elevation data with 30 arcsec spatial resolution as processed by WorldClim v2.1 (Fick \& Hijmans, 2017). We downloaded climate summary data for the period between 1970-2000 at 30 arcsec resolution from WorldClim v2.1 (Fick \& Hijmans, 2017). We focused on climate variables that might better differentiate desert environments due to limiting effects on biodiversity. These include Annual Precipitation, Annual Temperature, Mean Diurnal Range and Precipitation of the Driest Month. Additionally, we downloaded the WorldClim data derived Aridity and Potential Evapotranspiration data from the CGIAR Consortium for Spatial Information (v.2; Zomer et al., 2008; Trabucco \& Zomer, 2019). The productivity data is based on the normalized difference vegetation index (NDVI) over a period between 1981 and 2015 summarized on the NDVI3g time series (v.1; Pinzon \& Tucker, 2014). We downloaded and processed the NDVI data with the 'gimms' R package (Detsch, 2020) by obtaining the monthly data with 5 arcmin spatial resolution and summarizing the yearly data with maximum NDVI found. The final dataset is the average of the year maximum NDVI for the period between 1981 and 2015.

We spatially aggregated the environmental variables to match the target spatial resolution of the richness grid (10 arcmin $\sim 18 \mathrm{~km})$. We used the mean and standard deviation as aggregating function and derived three variables from each downloaded environmental descriptor: 1) mean aggregated value describing the average value at each pixel in the target resolution, 2) within-pixel standard deviation describing the variation within the target pixel, which represents regional heterogeneity, and 3) neighborhood standard deviation describing the surrounding variation to the target pixel. We chose two neighbors, equivalent to a $5 \times 5$ pixels search window at the target resolution, to produce the last variable. This variable describes how the surrounding environment might contribute to the species richness, as an additional estimation of environmental spatial heterogeneity. All spatial processing was performed with the raster R library (Hijmans, 2020). 


\section{Correlation between species richness and environmental descriptors}

In order to quantify the relation between species richness and environmental descriptors, we used a non-parametric Kendall correlation score under a randomized sub-sampling framework. We conducted correlation tests between species richness and each of the environmental variables, separately for each desert and combining all deserts together. For each environmental predictor, we conducted three different tests, corresponding to the three aggregation types (mean value, standard deviation within pixel, and neighborhood standard deviation; see Regional richness and environmental variables). For each test, we used 250 randomly selected pixels from each desert to calculate the correlation and repeated the process 1,000 times. The advantages of this framework are two-fold: first, it allows to compare same sample size, independently of the size of the desert; second, by randomly selecting scattered pixels over the desert area we decrease the effect of spatial autocorrelation of both species richness and the environmental descriptors on the correlation score. From the set with the correlation scores from each replicate, we calculated the average correlation and the respective $95 \%$ confidence interval. All analyses and data visualization were implemented with the $\mathrm{R}$ packages raster (Hijmans, 2020), rgdal (Bivand et al., 2019), and the data science collection tidyverse (Wickham et al., 2019).

\section{RESULTS}

\section{Biogeographic-scale lizard diversity}

Out of 6,303 global lizard species in the Roll et al. (2017) dataset, we identified 58 species from the Atacama Desert, 316 from the Australian deserts, 41 from the Central Asian desert, 26 from the Gobi, 207 from the Kalahari, 191 from the North American deserts, 133 from the Persian desert and 249 from the Saharo-Arabian desert (Figure 2a). As expected, arid Australia's lizard richness is the highest among the deserts of the world. Diversity in the Saharo-Arabian desert and in the Kalahari is also noteworthy, with more than 200 species each. The Gobi and the Central Asian deserts have the lowest diversity overall, while the North American and Persian deserts have intermediate richness (Figure 2a).

\section{Speciation rate and geographic area}

We found significant differences in speciation rates (DR metric) across desert regions (Kruskal-Wallis chi-squared $=186.12$, df $=7$, p-value $<0.001$ ), with highest rates in the Atacama desert and lowest in the Kalahari (Figure 2b). The post-hoc Wilcoxon test shows the pairwise differences between deserts (Table S1). We found no relationship between species richness and speciation rate, since levels of species richness are not reflected in rate values (Figure 2a, b). Lizards inhabiting the most diverse deserts (Australian, Saharo-Arabian, Kalahari, American) do not show particularly high speciation rates. This decoupling is also true for systems with low lizard diversity: Atacama desert, one of the least diverse, is inhabited by taxa with the highest speciation rates.

We found no effect of geographic area on biogeographic species richness or speciation rates (Figure 2). Regarding the richness-area relationship, the Kalahari desert, which is one of the most diverse, is the smallest one after the Atacama. In the other extreme, the SaharoArabian desert, of unparalleled extension, has lower diversity than Australia, and only few more species than much smaller deserts such as the North American and the Kalahari (Figure $2 \mathrm{a}, \mathrm{c})$. In respect of the area-speciation rate relationship, large deserts such as the SaharoArabian and the Australian do not present higher speciation rates than smaller ones such as the Atacama or the North American desert (Figure 2b, c). 
a

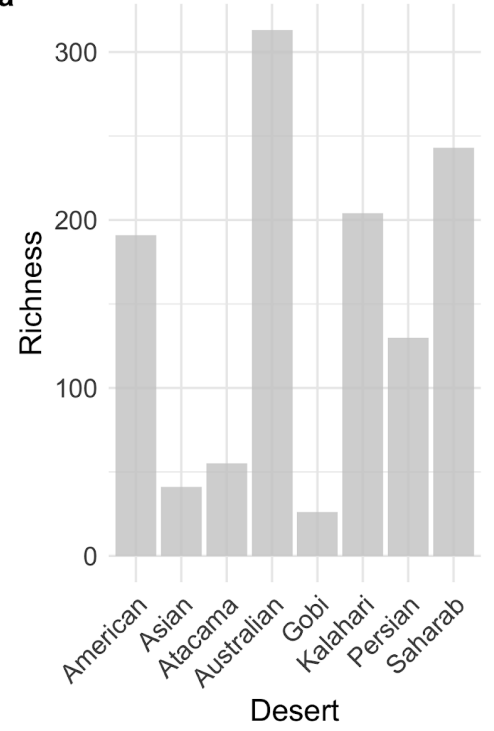

b

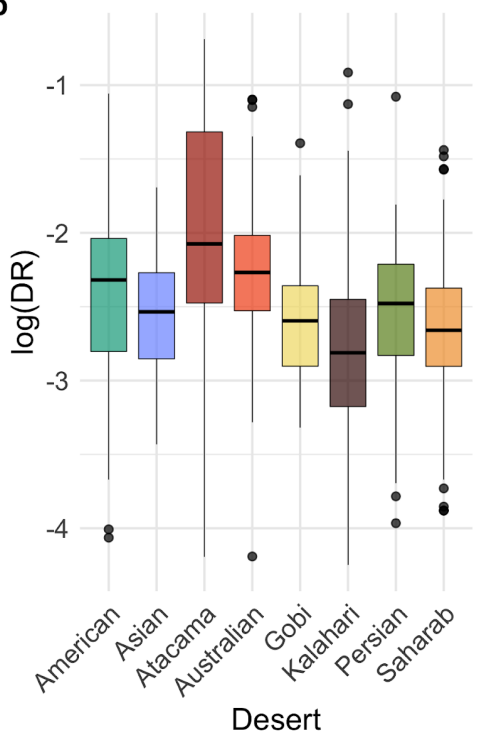

C

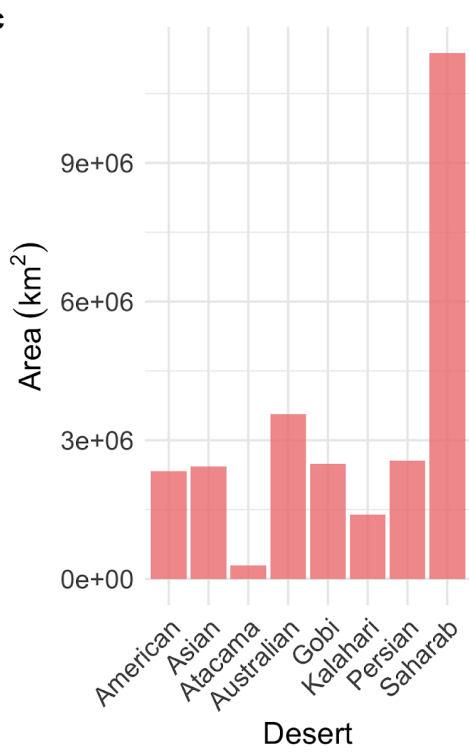

Figure 2. Biogeographic lizard richness (a), speciation rates (b) and geographic area (c) of arid systems worldwide. There is no clear trend in the relationship between these three attributes: highly diverse deserts (e.g., Australian) are not characterized by especially high speciation rates, while several smaller and less diverse deserts (e.g., Atacama) show higher speciation rates than more diverse ones (e.g., Kalahari). Speciation rate summaries (b) show median, interquartile range, total range and outliers for each desert system.

\section{Evolutionary time hypothesis}

The ancestral state reconstruction for desert occupancy (Figure S2) allowed us to estimate the age at which desert lizard diversity started accumulating and how the number of arid-adapted lineages has increased through time according to the reconstructed node probabilities (Figure 3 shows lineage accumulation in the four most diverse deserts). Among the deserts with higher species diversity, the Saharo-Arabian is the one in which lineages started accumulating earlier, around 50 million years ago (Ma). The number of lineages in the Kalahari and the North American deserts started increasing soon after, between 40 and 50 Ma. In contrast, arid Australian lineages did not begin diversifying until roughly $30 \mathrm{Ma}$. The number of lineages in the reconstructed lineage-through-time plot is lower in Australia at $20 \mathrm{Ma}$ than for any of the other major arid regions shown in Figure 2. 


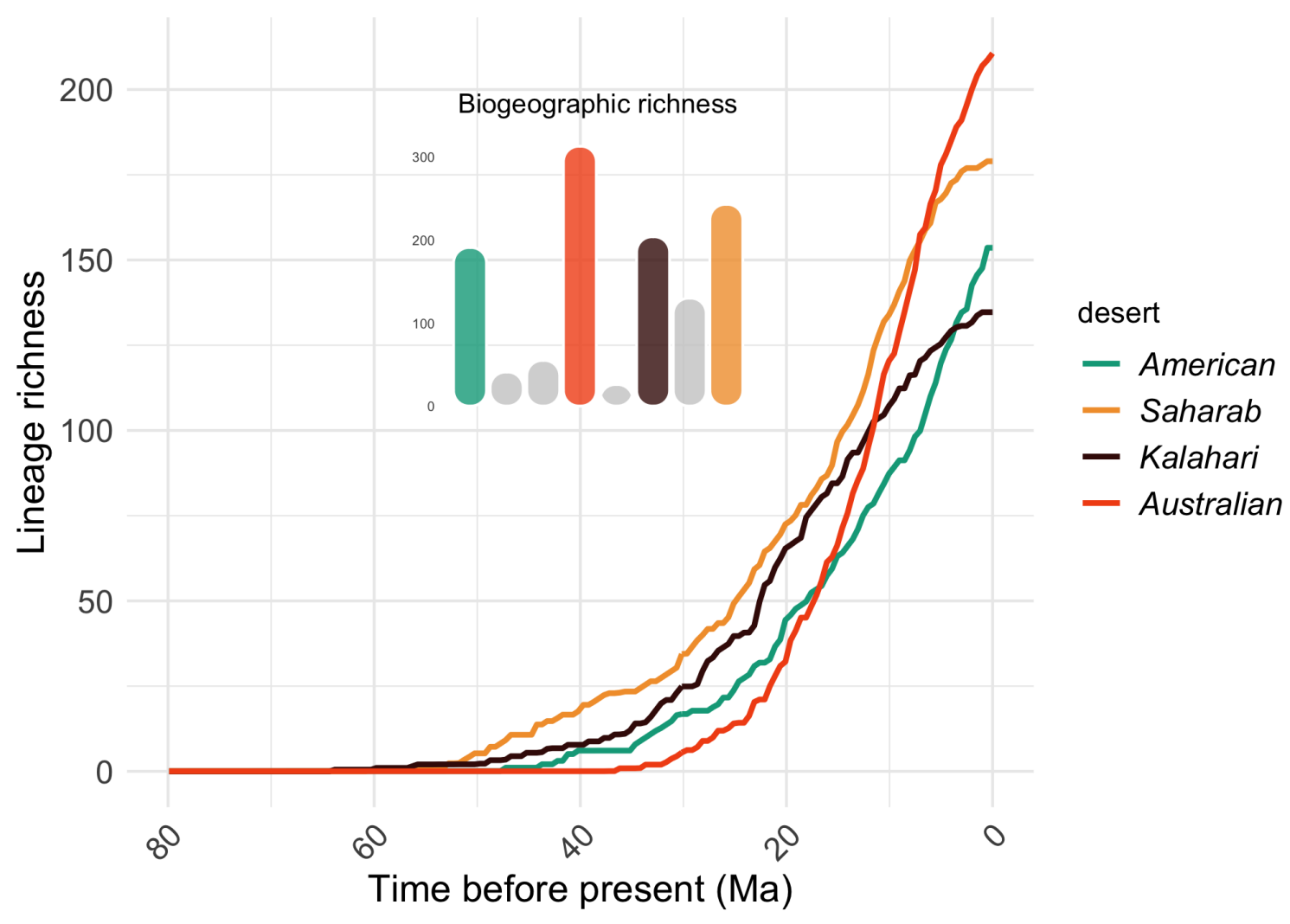

Figure 3. Accumulation of species richness through time in the four most diverse arid systems: North American, Australian, Kalahari and Saharo-Arabian deserts. Lineage richness is the cumulative probability of the focal state (arid region) summed over all nodes in the phylogeny that diverged prior to a given time point. This method will necessarily underestimate true richness at a given time as it cannot accommodate extinct (unobserved) lineages, but nonetheless tracks the temporal accumulation of present-day lineages (extant) through time within regions. Remarkably, the most-species rich region (Australia) is associated with the most recent faunal buildup, thus rejecting the hypothesis that Australia's exceptional diversity can be explained by greater time for diversity to accumulate.

\section{Regional lizard richness and the effect of environmental variables}

In our regional lizard diversity grid we found the expected outstanding levels in Australia, with most of the arid Australian grid cells containing between 60 and 80 species (Figure 4). Regional diversity levels are medium in the North American and the Kalahari deserts, and they are low for the rest of the arid systems, especially the Gobi and the Atacama deserts, with few or no grid cells having more than 20 species. This result indicates that the moderate-to-high overall (biogeographic) species richness for the Saharo-Arabian Desert (Figure 2a) is largely a result of the vastly greater area of that region. After controlling for sampling area (Figure 4), it is clear that regional assemblages in Saharo-Arabia contain far fewer species than arid Australia and the Kalahari. 


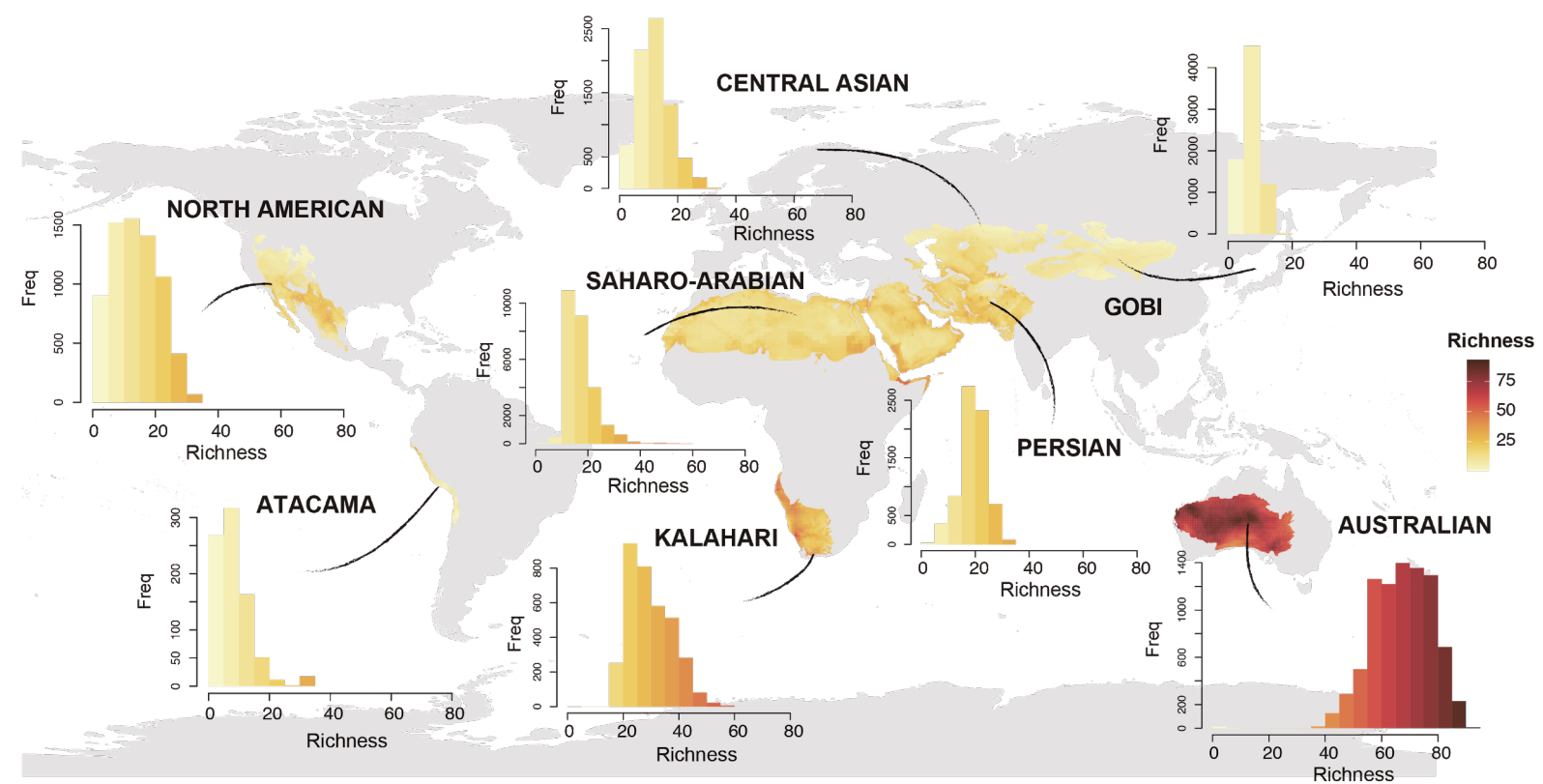

Figure 4. Regional lizard species richness (10 arc-minute grid cell) for the deserts of the world, with histograms of grid-cell richness for each system. Species richness of regional lizard assemblages from Australia is far greater than in any other arid region, and the system is thus exceptionally diverse at local (Pianka, 1969), regional, and biogeographic (Figure 2) scales.

None of the environmental variables analyzed (Annual Precipitation, Annual Temperature, Productivity, Elevation, Mean Diurnal Temperature Range, Precipitation in the Driest Month, Aridity, and Evapotranspiration), in any aggregation type (average, heterogeneity within, and surrounding heterogeneity) showed a strong correlation with regional lizard richness across the deserts (Figure 5; Table S2). Average values of evapotranspiration and annual temperature are the variables most related to richness, with a positive correlation with richness (Kendall's Tau $0.47 \pm 0.02$ and $0.46 \pm 0.02$, respectively). Neither of the heterogeneity variables plays a significant role in explaining lizard richness in arid regions worldwide.

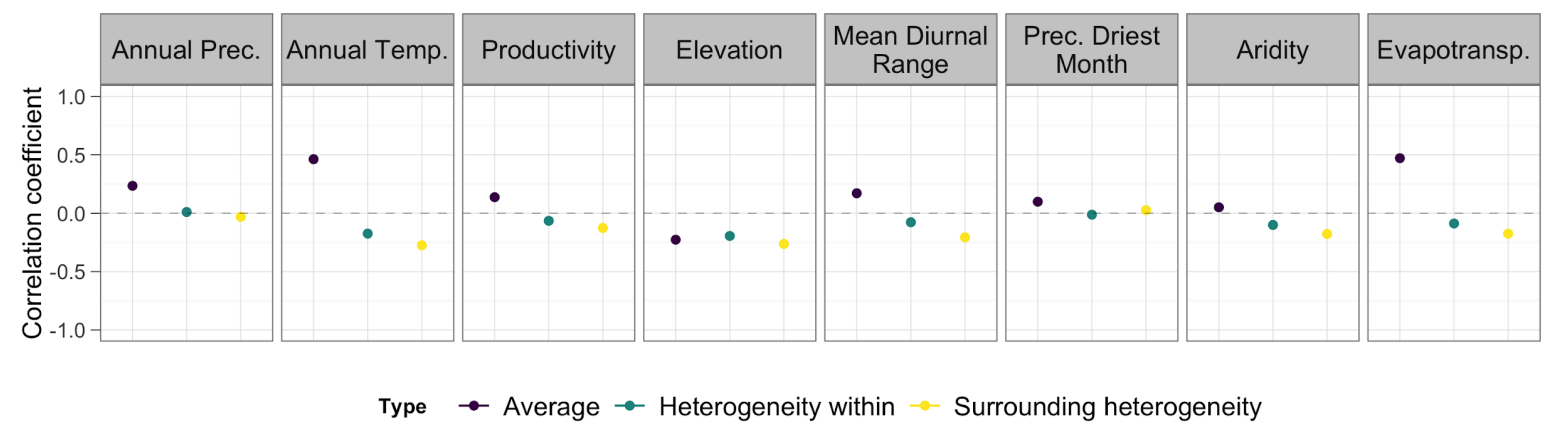

Figure 5. Correlation coefficient between regional richness and eight broad-scale environmental descriptors, combined across all desert regions. The points displayed encompass the mean and the $95 \%$ confidence interval from 1,000 replicates of the correlation tests. For each descriptor, three types of variables were tested: 1) 'Average': pixel average value, 2) 'Heterogeneity within': within-pixel heterogeneity (standard deviation), and 3) 'Surrounding heterogeneity': heterogeneity in the surrounding pixels. Mean annual temperature and evapotranspiration are the most explanatory descriptors, but none of the variables shows a strong relationship with regional richness. 
bioRxiv preprint doi: https://doi.org/10.1101/2021.02.09.430433; this version posted February 10, 2021. The copyright holder for this

preprint (which was not certified by peer review) is the author/funder, who has granted bioRxiv a license to display the preprint in perpetuity. It is made available under aCC-BY-NC-ND 4.0 International license.

We found no consistent effects of the environmental descriptors or aggregation types on regional (grid-cell) assemblages within individual deserts (Figure 6; Table S3). The most notable relationships included a positive correlation of average evapotranspiration with lizard richness in the Central Asian and North American deserts (Kendall's Tau 0.67 \pm 0.04 and $0.60 \pm 0.06$, respectively); a positive correlation of average annual temperature in the Central Asian and the Gobi deserts (Kendall's Tau $0.64 \pm 0.05$ and $0.63 \pm 0.05$, respectively); and a negative correlation of average precipitation of the driest month in the Central Asian desert (Kendall's Tau $-0.61 \pm 0.05$ ). 


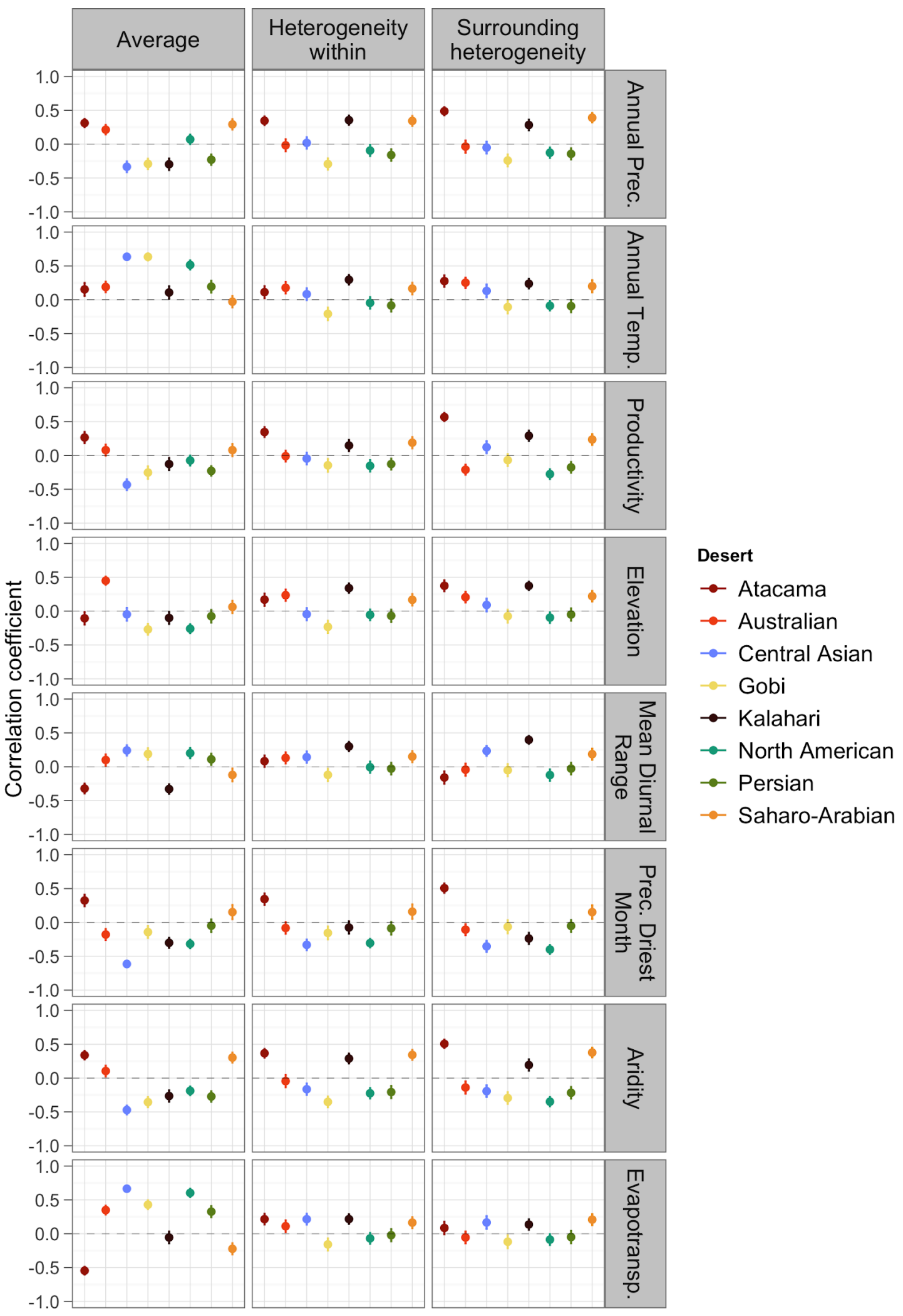

Figure 6. Correlation coefficient (mean and 95\% confidence interval from 1,000 bootstrap replicates) between each environmental descriptor and regional lizard richness, for each arid region separately. "Average" column gives the correlations between species richness and the mean of the environmental variable per cell. "Heterogeneity within" and "Surrounding heterogeneity" give the correlation between species richness and two measures of variability 
in environmental conditions per cell: the standard deviation of the variable in the cell, and the standard deviation of the variable in the surrounding cells, respectively. There are no consistent effects of the environmental variables across deserts, and no clear relationships between environment and richness.

\section{DISCUSSION}

Our results corroborate the uneven distribution of lizards across the deserts of the world and further highlight the exceptional lizard richness reported previously for arid Australia (Pianka, 1969, 1986; Roll et al., 2017), and illustrate how this pattern holds at both regional (Figure 4) and biogeographic (Figure 2) scales. Australia represents one extreme of the lizard diversity continuum among the deserts of the world, where we find some systems with medium levels of biogeographic and regional diversity, such as the North American or the Kalahari deserts, and very low levels in the other extreme, represented by deserts such as the Gobi and the Atacama. There are also cases of contrasting richness levels at different scales: the SaharoArabian region harbors high richness at the biogeographic scale but is relatively depauperate at the regional (grid-cell) scale. However, our results do not corroborate some current hypotheses explaining species diversity patterns in the deserts (Table 1). Specifically, we find no evidence that recent speciation rates are fastest in the most species-rich deserts (Figure 2) and no evidence that the most species-rich deserts have accumulated species for longer (evolutionary time hypothesis; Figure 3). Furthermore, we found little evidence that the differences in species richness among deserts at biogeographic and regional scales are the result of the many environmental factors we considered (Figures 5 and 6).

Speciation is one of the main processes that directly influence the number of species at large scales (Ricklefs, 1987; Jetz \& Fine, 2012; Schluter \& Pennell, 2017). The idea of an immediate relationship between speciation rate and species richness (i.e., high levels of species richness are primarily the result of high speciation rates) is a long-standing hypothesis (MacArthur, 1969; Mittelbach et al., 2007) and has proven useful to explain the latitudinal diversity gradient in mammals (Rolland et al., 2014), but it has been recently challenged in global analyses of other major groups such as fishes (Rabosky et al., 2018), birds (Jetz et al., 2012; Kennedy et al., 2014; Rabosky et al., 2015; Quintero \& Jetz, 2018), and plants (Igea \& Tanentzap, 2020). The "faster speciation" hypothesis was proposed by Pianka (1972) to explain Australia's extreme lizard diversity, but our study represents the first formal test of this idea. We found no relationship between high species richness and high speciation rates, suggesting that the exceptionally high diversity in arid Australia is not driven by faster speciation. Likewise, deserts with low species richness (e.g., Gobi and Central Asian) did not yield particularly low speciation rates. In fact, speciation can sometimes be faster in the regions with lowest diversity (Rabosky et al., 2018). Such decoupling might reflect the greater importance of extinction or immigration relative to speciation (Gaston \& Blackburn, 1996; Lopez et al., 2019; Meseguer \& Condamine, 2020), and/or the importance of differential carrying capacities and diversity-dependence in mediating overall diversity patterns (Marshall, 2007; Mittelbach et al., 2007; Rabosky, 2009).

It is important to note that our analyses concern present-day speciation rates only and we did not attempt to estimate net diversification rates. Net diversification rates require estimates of extinction, which is notoriously difficult in the absence of fossils (Rabosky, 2016). Moreover, we did not attempt to reconstruct historical speciation rates, which might have been faster in the past; recent work has emphasized the considerable challenges that face reconstructions of speciation rate early in the history of evolutionary radiations (Louca \& Pennell, 2020). Nonetheless, analyses of recent speciation rates can still provide great insight 
into the causes of diversity gradients. Processes underlying patterns of species richness can be affected by mechanisms that are time- and diversity-independent. For example, faster speciation could result from the kinetic effects of temperature on processes that favor reproductive isolation (e.g., effects on metabolism; Rohde, 1992; Allen et al., 2002) and as such, low-latitude deserts should be characterized by faster speciation rates than higher-latitude deserts. The shifting sandridge hypothesis of Pianka (1972) proposes that the mobile dune sheets within interior Australia serve as a continued source of geographic isolation for nondune taxa - in effect, creating a continued "species pump" that will result in overall high rates of speciation for the arid Australian biota. Our finding of unexceptional speciation rates for the Australian deserts rejects this and other species-pump models for this system. Note that this does not mean that such shifting sandridges are unimportant for speciation, merely that speciation rates as influenced by such geomorphic/landscape processes are unlikely to serve as rate-limiting controls on species richness.

Geographic area is one of the main factors that may affect broad-scale patterns of species richness (Connor \& McCoy, 1979). The concept of the species-area relationship, derived from early works (Gleason, 1922, 1925) and developed later from the island biogeography theory (MacArthur \& Wilson, 1967), predicts a positive effect of geographic area on both species diversity and speciation rates (Rosenzweig, 1992; Rosenzweig \& Sandlin, 1997). This has been supported for island and non-island systems (Sepkoski, 1976; Marshall et al., 1982; Losos \& Schluter, 2000; Kisel \& Barraclough, 2010; Wagner et al., 2014), although patterns reported for some systems have likely been confounded by assumptions that speciation rates are invariant through time (Rabosky \& Glor, 2010). Overall, the effect of area on broad diversity patterns, such as the latitudinal gradient, and the assumptions of the "area model" remain obscure (Rohde, 1992, 1998; Chown \& Gaston, 2000). We found no significant effect of geographic area on desert lizard richness or speciation rates, consistent with recent studies that have found no evidence for faster speciation in the large humid tropics (Jetz et al., 2012; Igea \& Tanentzap, 2020).

Alternatively, evolutionary time may generate diversity patterns in which species richness is decoupled from geographic area and other factors (Rohde, 1986; Stephens \& Wiens, 2003), although some evidence supports the combined effect of area and time (Fine \& Ree, 2006; Jetz \& Fine, 2012). Age differences between geographic regions or biomes has long been thought to be a potential contributor to differences in species richness (Wallace, 1878), for the simple reason that older, less-disturbed geographic regions had longer periods of time for diversity to accumulate (Fischer, 1960; Mittelbach et al., 2007). Our results argue against any simple role for time in explaining the observed heterogeneity in desert lizard richness. Remarkably, our results suggest that Australian lizard diversity began accumulating approximately ten million years after the onset of lineage accumulation in less-diverse deserts (Figure 3). Thus, greater time for diversification is unlikely to account for the extreme lizard richness observed in arid Australia. It is worth noting that our estimation of the age of aridadapted lineages does not aim to serve as an absolute date for desert origination. The ages of the deserts considered here is a complex and contentious issue (e.g., Swezey, 2006). The onset of arid conditions might have greatly preceded the formation of many modern-day arid landscapes (Schuster et al., 2006; Pillans, 2018), and hence could potentially explain the presence of arid-adapted lineages long before the estimated geological age of the desert (Byrne et al., 2008; Carranza et al., 2008). Therefore, our estimation of the age of arid-adapted lineages does not aim to serve as an absolute date for desert origination, but instead as a relative time framework to compare the biotas inhabiting different desert systems.

Despite theoretical and empirical support linking climate and topography to species richness in general (Wright, 1983; Currie, 1991; Jetz \& Rahbek, 2002; Francis \& Currie, 2003; Kreft \& Jetz, 2007; Qian, 2010; Skeels et al., 2019), we found ambiguous support for the effects 
of environmental variables on desert lizard diversity at both regional and biogeographic scales. In our analyses merging all arid regions together, we found certain positive correlations between regional species richness and two of the environmental descriptors: average potential evapotranspiration and average annual temperature (Figure 5). Additionally, our per-desert disaggregated analyses show differential effects of the environmental descriptors on lizard richness across deserts. We found a considerable correlation of richness in some deserts with several variables, in particular average evapotranspiration in Central Asia and North America, average annual temperature in Central Asia and the Gobi, and (negative) average precipitation of the driest month in Central Asia. Thus, the impact of the environment on the distribution of lizard diversity in the Central Asian desert seems stronger than in other arid systems. It is interesting to note the shared patterns in the Central Asian and the Gobi desert with respect to most variables. Both deserts have similar levels of diversity (very low biogeographic and regional diversity), and this might indicate a differential role of climate and other factors between high- and low-diversity systems. In the Atacama desert, environmental heterogeneity (e.g., surrounding heterogeneity in precipitation, productivity and aridity) appears to play a significant role in the distribution of diversity. Average elevation is more related with the higher diversity in Australia than any other variable, and its importance for Australian lizards is remarkable in comparison with other deserts, while in the Kalahari and the Atacama deserts the elevational heterogeneity seems more relevant. Additionally, in the Kalahari, heterogeneity plays a rather constant role. In the Saharo-Arabian region, on the contrary, there are not remarkable effects of the variables tested on lizard distribution.

We did not find consistent effects of climate, productivity, and topography on species richness across deserts, but it is possible that other, unmeasured environmental variables and their interactions provide an important control on broad-scale richness. Our results are consistent with a scenario in which desert lizard diversity at regional-to-biogeographic scales depends mainly on system-specific ecological dynamics. Factors such as extinction, habitat heterogeneity, or ecological preferences and interactions, might be playing a relevant role in shaping the distribution of current lizard diversity in the deserts. Our results provide evidence against several general hypotheses proposed to explain desert lizard diversity patterns (age; evolutionary rate). However, we only studied part of the evolutionary rates hypothesis (speciation), and we speculate that the relationship between richness and environment may not be adequately captured with our simplified set of eight explanatory variables. Ultimately, our results emphasize the complexity of evolutionary and ecological processes that determine large-scale diversity patterns. Disentangling their underlying causes remains an essential task and one that is necessary in order to face the challenges imposed by the rapid pace of climatic and other change that is disrupting ecosystems worldwide.

\section{DATA AND CODE AVAILABILITY}

All data and code produced for this study are openly available at a public repository.

\section{FUNDING}

This work has been funded by grants CGL2015-70390-P (MINECO/FEDER, UE) Spain and PGC2018-098290-B-I00 (MCIU/AEI/FEDER, UE) Spain. HTC was funded by an FPI grant from the Ministerio de Economía y Competitividad, Spain (BES-2016-078341). 


\section{ACKNOWLEDGEMENTS}

We want to thank Pascal O. Title and Joan Garcia-Porta for their help with spatial analyses, and Iris Menéndez for her insightful comments on the text and figures.

\section{REFERENCES}

Allen, A.P., Brown, J.H. \& Gillooly, J.F. (2002) Global biodiversity, biochemical kinetics, and the energetic-equivalence rule. Science, 297, 1545-1548.

Antão, L.H., Bates, A.E., Blowes, S.A., Waldock, C., Supp, S.R., Magurran, A.E., Dornelas, M. \& Schipper, A.M. (2020) Temperature-related biodiversity change across temperate marine and terrestrial systems. Nature Ecology and Evolution.

Badgley, C., Smiley, T.M., Terry, R., Davis, E.B., DeSantis, L.R.G., Fox, D.L., Hopkins, S.S.B., Jezkova, T., Matocq, M.D., Matzke, N., McGuire, J.L., Mulch, A., Riddle, B.R., Roth, V.L., Samuels, J.X., Strömberg, C.A.E. \& Yanites, B.J. (2017) Biodiversity and Topographic Complexity: Modern and Geohistorical Perspectives. Trends in Ecology and Evolution, 32, 211-226.

Belmaker, J. \& Jetz, W. (2015) Relative roles of ecological and energetic constraints, diversification rates and region history on global species richness gradients. Ecology Letters, 18, 563-571.

Bivand, R., Keitt, T. \& Rowlingson, B. (2019) rgdal: Bindings for the "Geospatial" Data Abstraction Library.

Byrne, M., Yeates, D.K., Joseph, L., Kearney, M., Bowler, J., Williams, M.A.J., Cooper, S., Donnellan, S.C., Keogh, J.S., Leys, R., Melville, J., Murphy, D.J., Porch, N. \& Wyrwoll, K.H. (2008) Birth of a biome: Insights into the assembly and maintenance of the Australian arid zone biota. Molecular Ecology, 17, 4398-4417.

Cantalapiedra, J.L., Domingo, M.S. \& Domingo, L. (2018) Multi-scale interplays of biotic and abiotic drivers shape mammalian sub-continental diversity over millions of years. Scientific Reports, 8, 13413.

Carranza, S., Arnold, E.N., Geniez, P., Roca, J. \& Mateo, J.A. (2008) Radiation, multiple dispersal and parallelism in the skinks, Chalcides and Sphenops (Squamata: Scincidae), with comments on Scincus and Scincopus and the age of the Sahara Desert. Molecular Phylogenetics and Evolution, 46, 1071-1094.

Chang, J., Rabosky, D.L. \& Alfaro, M.E. (2020) Estimating Diversification Rates on Incompletely Sampled Phylogenies: Theoretical Concerns and Practical Solutions. Systematic Biology, 69, 602-611.

Chown, S.L. \& Gaston, K.J. (2000) Areas, cradles and museums: the latitudinal gradient in species richness. Trends in Ecology and Evolution, 15, 311-315.

Connor, E.F. \& McCoy, E.D. (1979) The Statistics and Biology of the Species-Area Relationship. The American Naturalist, 113, 791-833.

Couvreur, T.L.P. (2015) Odd man out: why are there fewer plant species in African rain forests? Plant Systematics and Evolution, 301, 1299-1313.

Cracraft, J. (1992) Explaining Patterns of Biological Diversity: Integrating Causation at Different Spatial and Temporal Scales. Systematics, Ecology and the Biodiversity Crisis, pp. 59-76.

Currie, D.J. (1991) Energy and large-scale patterns of animal and plant species richness. The American Naturalist, 137, 27-49.

Detsch, F. (2020) gimms: Download and Process GIMMS NDVI3g Data,.

Duellman, W.E. (2005) Cusco Amazónico, Comstock Pub. Associates. 
Etienne, R.S., Cabral, J.S., Hagen, O., Hartig, F., Hurlbert, A.H., Pellissier, L., Pontarp, M. \& Storch, D. (2019) A minimal model for the latitudinal diversity gradient suggests a dominant role for ecological limits. American Naturalist, 194, E122-E133.

Fick, S.E. \& Hijmans, R.J. (2017) WorldClim 2: new 1-km spatial resolution climate surfaces for global land areas. International Journal of Climatology, 37, 4302-4315.

Fine, P.V.A. \& Ree, R.H. (2006) Evidence for a time-integrated species-area effect on the latitudinal gradient in tree diversity. American Naturalist, 168, 796-804.

Fischer, A.G. (1960) Latitudinal variations in organic diversity. Evolution, 14, 64-81.

Francis, A.P. \& Currie, D.J. (2003) A globally consistent richness-climate relationship for angiosperms. The American Naturalist, 161, 523-536.

Garcia-Porta, J., Irisarri, I., Kirchner, M., Rodríguez, A., Kirchhof, S., Brown, J.L., MacLeod, A., Turner, A.P., Ahmadzadeh, F., Albaladejo, G., Crnobrnja-Isailovic, J., De la Riva, I., Fawzi, A., Galán, P., Göçmen, B., Harris, D.J., Jiménez-Robles, O., Joger, U., Jovanović Glavaš, O., Karış, M., Koziel, G., Künzel, S., Lyra, M., Miles, D., Nogales, M., Oğuz, M.A., Pafilis, P., Rancilhac, L., Rodríguez, N., Rodríguez Concepción, B., Sanchez, E., Salvi, D., Slimani, T., S'khifa, A., Qashqaei, A.T., Žagar, A., Lemmon, A., Moriarty Lemmon, E., Carretero, M.A., Carranza, S., Philippe, H., Sinervo, B., Müller, J., Vences, M. \& Wollenberg Valero, K.C. (2019) Environmental temperatures shape thermal physiology as well as diversification and genome-wide substitution rates in lizards. Nature Communications, 10, 4077.

Gaston, K.J. \& Blackburn, T.M. (1996) The tropics as a museum of biological diversity: An analysis of the New World avifauna. Proceedings of the Royal Society B: Biological Sciences, 263, 63-68.

Gleason, H.A. (1922) On the Relation Between Species and Area. Ecology, 3, 158-162.

Gleason, H.A. (1925) Species and Area. Ecology, 6, 66-74.

Harmon, L.J., Weir, J.T., Brock, C.D., Glor, R.E. \& Challenger, W. (2008) GEIGER: Investigating evolutionary radiations. Bioinformatics, 24, 129-131.

Hijmans, R.J. (2020) raster: Geographic Data Analysis and Modeling.

Igea, J. \& Tanentzap, A.J. (2020) Angiosperm speciation cools down in the tropics. Ecology Letters, 23, 692-700.

Jablonski, D., Huang, S., Roy, K. \& Valentine, J.W. (2017) Shaping the Latitudinal Diversity Gradient: New Perspectives from a Synthesis of Paleobiology and Biogeography. The American Naturalist, 189, 1-12.

James, C.D. \& Shine, R. (2000) Why are there so many coexisting species of lizards in Australian deserts? Oecologia, 125, 127-141.

Jetz, W. \& Fine, P.V.A. (2012) Global gradients in vertebrate diversity predicted by historical area-productivity dynamics and contemporary environment. PLoS Biology, 10.

Jetz, W. \& Rahbek, C. (2002) Geographic range size and determinants of avian species richness. Science, 297, 1548-1551.

Jetz, W., Thomas, G.H., Joy, J.B., Hartmann, K. \& Mooers, A.O. (2012) The global diversity of birds in space and time. Nature, 491, 444-448.

Kelt, D.A., Brown, J.H., Heske, E.J., Marquet, P.A., Morton, S.R., Reid, J.R.W., Kontantín, A.R. \& Shenbrot, G. (1996) Community Structure of Desert Small Mammals: Comparisons Across Four Continents. Ecology, 77, 746-761.

Kennedy, J.D., Wang, Z., Weir, J.T., Rahbek, C., Fjelds $\backslash a a$, J. \& Price, T.D. (2014) Into and out of the tropics: The generation of the latitudinal gradient among New World passerine birds. Journal of Biogeography, 41, 1746-1757.

Kisel, Y. \& Barraclough, T.G. (2010) Speciation has a spatial scale that depends on levels of gene flow. The American Naturalist, 175, 316-334. 
Kreft, H. \& Jetz, W. (2007) Global patterns and determinants of vascular plant diversity. Proceedings of the National Academy of Sciences of the United States of America, 104, 5925-5930.

Latham, R.E. \& Ricklefs, R.E. (1993) Continental comparisons of temperate-zone tree species diversity. Species Diversity in Ecological Communities: Historical and Geographical Perspectives (ed. by R.E. Ricklefs) and D. Schluter), pp. 294-313. University of Chicago Press.

Lopez, K., Karen López-Estrada, E., Sanmartín, I., García-París, M. \& Zaldívar-Riverón, A. (2019) High extinction rates and non-adaptive radiation explains patterns of low diversity and extreme morphological disparity in North American blister beetles (Coleoptera, Meloidae). Molecular Phylogenetics and Evolution, 130, 156-168.

Losos, J.B. \& Schluter, D. (2000) Analysis of an evolutionary species-area relationship. Nature, 408, 847-850.

Louca, S. \& Pennell, M.W. (2020) Extant timetrees are consistent with a myriad of diversification histories. Nature, 11.

MacArthur, R.H. (1969) Patterns of communities in the tropics. Biological Journal of the Linnean Society, 1, 19-30.

MacArthur, R.H. \& Wilson, E.O. (1967) The theory of island biogeography, Princeton university press.

Mahler, D.L., Revell, L.J., Glor, R.E. \& Losos, J.B. (2010) Ecological opportunity and the rate of morphological evolution in the diversification of Greater Antillean anoles. Evolution, 64, 2731-2745.

Marshall, C.R. (2007) Explaining Latitudinal Diversity Gradients. Science, 317, 451-452.

Marshall, L.G., Webb, S.D., Sepkoski, J.J. \& Raup, D.M. (1982) Mammalian evolution and the Great American Interchange. Science, 215, 1351-1357.

Menéndez, I., Gómez Cano, A.R., Cantalapiedra, J.L., Peláez-Campomanes, P., ÁlvarezSierra, M.A. \& Hernández Fernández, M. (2020) A multi-layered approach to the diversification of squirrels. Mammal Review.

Meseguer, A.S. \& Condamine, F.L. (2020) Ancient tropical extinctions at high latitudes contributed to the latitudinal diversity gradient. Evolution, 2.

Mittelbach, G.G., Schemske, D.W., Cornell, H.V., Allen, A.P., Brown, J.M., Bush, M.B., Harrison, S.P., Hurlbert, A.H., Knowlton, N., Lessios, H.A., McCain, C.M., McCune, A.R., McDade, L.A., McPeek, M.A., Near, T.J., Price, T.D., Ricklefs, R.E., Roy, K., Sax, D.F., Schluter, D., Sobel, J.M. \& Turelli, M. (2007) Evolution and the latitudinal diversity gradient: Speciation, extinction and biogeography. Ecology Letters, 10, 315331.

Morton, S.R. \& James, C.D. (1988) The Diversity and Abundance of Lizards in Arid Australia: A New Hypothesis. The American Naturalist, 132, 237-256.

Olson, D.M., Dinerstein, E., Wikramanayake, E.D., Burgess, N.D., Powell, G.V.N., Underwood, E.C., D’amico, J.A., Itoua, I., Strand, H.E., Morrison, J.C., Loucks, C.J., Allnutt, T.F., Ricketts, T.H., Kura, Y., Lamoreux, J.F., Wettengel, W.W., Hedao, P. \& Kassem, K.R. (2001) Terrestrial Ecoregions of the World: A New Map of Life on Earth. BioScience, 51, 933-933.

Pianka, E.R. (1989) Desert lizard diversity: additional comments and some data. The American Naturalist, 134, 344-364.

Pianka, E.R. (1986) Ecology and Natural History of Desert Lizards, Princeton University Press.

Pianka, E.R. (1969) Habitat specificity, speciation, and species density in Australian desert lizards. Ecology, 50, 498-502.

Pianka, E.R. (1971) Lizard species density in the Kalahari desert. Ecology, 52, 1024-1029. 
Pianka, E.R. (1985) Some intercontinental comparisons of desert lizards. National Geographic Research, 1, 490-504.

Pianka, E.R. (1972) Zoogeography and speciation of Australian desert lizards: an ecological perspective. Copeia, 1, 127-145.

Pillans, B.J. (2018) Seeing Red: Some Aspects of the Geological and Climatic History of the Australian Arid Zone. On the Ecology of Australia's Arid Zone (ed. by H. Lambers), pp. 5-43. Springer International Publishing.

Pinzon, J.E. \& Tucker, C.J. (2014) A non-stationary 1981-2012 AVHRR NDVI3g time series. Remote Sensing, 6, 6929-6960.

Qian, H. (2010) Environment-richness relationships for mammals, birds, reptiles, and amphibians at global and regional scales. Ecological Research, 25, 629-637.

Qian, H. \& Ricklefs, R.E. (2000) Large-scale processes and the Asian bias in species diversity of temperate plants. Nature, 407, 180-182.

Quintero, I. \& Jetz, W. (2018) Global elevational diversity and diversification of birds. Nature, 555, 246-250.

R Core Team (2019) R: A Language and Environment for Statistical Computing, R Foundation for Statistical Computing, Vienna, Austria.

Rabosky, D.L. (2016) Challenges in the estimation of extinction from molecular phylogenies: A response to Beaulieu and O'Meara. Evolution, 70, 218-228.

Rabosky, D.L. (2009) Ecological limits and diversification rate: Alternative paradigms to explain the variation in species richness among clades and regions. Ecology Letters, 12 , $735-743$.

Rabosky, D.L. (2015) No substitute for real data: A cautionary note on the use of phylogenies from birth-death polytomy resolvers for downstream comparative analyses. Evolution, 69, 3207-3216.

Rabosky, D.L., Chang, J., Title, P.O., Cowman, P.F., Sallan, L., Friedman, M., Kaschner, K., Garilao, C., Near, T.J., Coll, M. \& Alfaro, M.E. (2018) An inverse latitudinal gradient in speciation rate for marine fishes. Nature, 559, 392-395.

Rabosky, D.L. \& Glor, R.E. (2010) Equilibrium speciation dynamics in a model adaptive radiation of island lizards. Proceedings of the National Academy of Sciences, 107, 22178-22183.

Rabosky, D.L. \& Hurlbert, A.H. (2015) Species Richness at Continental Scales Is Dominated by Ecological Limits. The American Naturalist, 185, 572-583.

Rabosky, D.L., von May, R., Grundler, M.C. \& Davis Rabosky, A.R. (2019) The Western Amazonian richness gradient for squamate reptiles: Are There Really Fewer Snakes and Lizards in Southwestern Amazonian Lowlands? Diversity, 11.

Rabosky, D.L., Title, P.O. \& Huang, H. (2015) Minimal effects of latitude on present-day speciation rates in New World birds. Proceedings of the Royal Society B: Biological Sciences, 282.

Revell, L.J. (2012) phytools: An R package for phylogenetic comparative biology (and other things). Methods in Ecology and Evolution, 3, 217-223.

Ricklefs, R.E. (2004) A comprehensive framework for global patterns in biodiversity. Ecology Letters, 7, 1-15.

Ricklefs, R.E. (1987) Community Diversity: relative roles of local and regional processes. Science, 235, 167-171.

Ricklefs, R.E. \& Latham, R.E. (1993) Global patterns of diversity in mangrove floras. Species Diversity in Ecological Communities: Historical and Geographical Perspectives (ed. by R.E. Ricklefs) and D. Schluter), pp. 215-229. University of Chicago Press.

Ricklefs, R.E. \& Schluter, D. (1993) Species diversity in ecological communities: historical and geographical perspectives, University of Chicago Press Chicago. 
Rohde, K. (1986) Differences in species diversity of Monogenea between the Pacific and Atlantic Oceans. Hydrobiologia, 137, 21-28.

Rohde, K. (1998) Latitudinal Gradients in Species Diversity. Area Matters, but How Much? Oikos, 82, 184-184.

Rohde, K. (1992) Latitudinal Gradients in Species Diversity: The Search for the Primary Cause. Oikos, 65, 514-527.

Roll, U., Feldman, A., Novosolov, M., Allison, A., Bauer, A.M., Bernard, R., Böhm, M., Castro-Herrera, F., Chirio, L., Collen, B., Colli, G.R., Dabool, L., Das, I., Doan, T.M., Grismer, L.L., Hoogmoed, M., Itescu, Y., Kraus, F., Lebreton, M., Lewin, A., Martins, M., Maza, E., Meirte, D., Nagy, Z.T., Nogueira, C.D.C., Pauwels, O.S.G., PincheiraDonoso, D., Powney, G.D., Sindaco, R., Tallowin, O.J.S., Torres-Carvajal, O., Trape, J.F., Vidan, E., Uetz, P., Wagner, P., Wang, Y., Orme, C.D.L., Grenyer, R. \& Meiri, S. (2017) The global distribution of tetrapods reveals a need for targeted reptile conservation. Nature Ecology and Evolution, 1, 1677-1682.

Rolland, J., Condamine, F.L., Jiguet, F. \& Morlon, H. (2014) Faster Speciation and Reduced Extinction in the Tropics Contribute to the Mammalian Latitudinal Diversity Gradient. PLoS Biology, 12.

Rosenzweig, M.L. (1992) Species Diversity Gradients: We Know More and Less Than We Thought. Journal of Mammalogy, 73, 715-730.

Rosenzweig, M.L. \& Sandlin, E.A. (1997) Species Diversity and Latitudes: Listening to Area's Signal. Oikos, 80, 172-176.

Schemske, D.W. \& Mittelbach, G.G. (2017) "Latitudinal Gradients in Species Diversity": Reflections on Pianka's 1966 Article and a Look Forward. American Naturalist, 189, 599-603.

Schluter, D. \& Pennell, M.W. (2017) Speciation gradients and the distribution of biodiversity. Nature, 546, 48-55.

Schuster, M., Duringer, P., Ghienne, J.F., Vignaud, P., Mackaye, H.T., Likius, A. \& Brunet, M. (2006) The age of the Sahara Desert. Science, 311, 821.

Sepkoski, J.J. (1976) Species diversity in the Phanerozoic: species-area effects. Paleobiology, 2, 298-303.

Skeels, A., Esquerré, D. \& Cardillo, M. (2019) Alternative pathways to diversity across ecologically distinct lizard radiations. Global Ecology and Biogeography, 1-16.

Stein, A., Beck, J., Meyer, C., Waldmann, E., Weigelt, P. \& Kreft, H. (2015) Differential effects of environmental heterogeneity on global mammal species richness. Global Ecology and Biogeography, 24, 1072-1083.

Stein, A., Gerstner, K. \& Kreft, H. (2014) Environmental heterogeneity as a universal driver of species richness across taxa, biomes and spatial scales. Ecology Letters, 17, 866880.

Stephens, P.R. \& Wiens, J.J. (2003) Explaining species richness from continents to communities: The time-for-speciation effect in emydid turtles. American Naturalist, 161, 112-128.

Swezey, C.S. (2006) Revisiting the age of the Sahara Desert. Science, 312, 1138-1139.

Thomas, G.H., Hartmann, K., Jetz, W., Joy, J.B., Mimoto, A. \& Mooers, A.O. (2013) PASTIS: An $\mathrm{R}$ package to facilitate phylogenetic assembly with soft taxonomic inferences. Methods in Ecology and Evolution, 4, 1011-1017.

Title, P.O. \& Rabosky, D.L. (2019) Tip rates, phylogenies and diversification: What are we estimating, and how good are the estimates? Methods in Ecology and Evolution, 2019, $1-14$. 
Tonini, J.F.R., Beard, K.H., Ferreira, R.B., Jetz, W. \& Pyron, R.A. (2016) Fully-sampled phylogenies of squamates reveal evolutionary patterns in threat status. Biological Conservation, 204, 23-31.

Trabucco, A. \& Zomer, R. (2019) Global Aridity Index and Potential Evapotranspiration (ET0) Climate Database v2.

Valente, L.M. \& Vargas, P. (2013) Contrasting evolutionary hypotheses between two mediterranean-climate floristic hotspots: The cape of southern Africa and the mediterranean basin. Journal of Biogeography, 40, 2032-2046.

Velasco, J.A., Villalobos, F., Diniz-Filho, J.A.F., Algar, A.C., Flores-Villela, O., Köhler, G., Poe, S. \& Martinez-Meyer, E. (2018) Climatic and evolutionary factors shaping geographical gradients of species richness in Anolis lizards. Biological Journal of the Linnean Society, 123, 615-627.

Wagner, C.E., Harmon, L.J. \& Seehausen, O. (2014) Cichlid species-area relationships are shaped by adaptive radiations that scale with area. Ecology Letters, 17, 583-592.

Wallace, A.R. (1878) Tropical nature, and other essays, Macmillan and Company.

Wang, L.G., Lam, T.T.Y., Xu, S., Dai, Z., Zhou, L., Feng, T., Guo, P., Dunn, C.W., Jones, B.R., Bradley, T., Zhu, H., Guan, Y., Jiang, Y. \& Yu, G. (2020) Treeio: An R Package for Phylogenetic Tree Input and Output with Richly Annotated and Associated Data. Molecular Biology and Evolution, 37, 599-603.

Weber, M.G., Wagner, C.E., Best, R.J., Harmon, L.J. \& Matthews, B. (2017) Evolution in a Community Context: On Integrating Ecological Interactions and Macroevolution. Trends in Ecology and Evolution, 32, 291-304.

Wickham, H., Averick, M., Bryan, J., Chang, W., McGowan, L., François, R., Grolemund, G., Hayes, A., Henry, L., Hester, J., Kuhn, M., Pedersen, T., Miller, E., Bache, S., Müller, K., Ooms, J., Robinson, D., Seidel, D., Spinu, V., Takahashi, K., Vaughan, D., Wilke, C., Woo, K. \& Yutani, H. (2019) Welcome to the Tidyverse. Journal of Open Source Software, 4, 1686.

Wiens, J.J. (2011) The causes of species richness patterns across space, time, and clades and the role of "ecological limits." Quarterly Review of Biology, 86, 75-96.

Wright, D.H. (1983) Species-Energy Theory: An Extension of Species-Area Theory. Oikos, 41, 496-496.

Zomer, R.J., Trabucco, A., Bossio, D.A. \& Verchot, L.V. (2008) Climate change mitigation: A spatial analysis of global land suitability for clean development mechanism afforestation and reforestation. Agriculture, Ecosystems and Environment, 126, 67-80. 